\title{
EPR Measurement of Fragmentation Kinetics in Dithiobenzoate-Mediated RAFT Polymerization
}

\author{
Wibke Meiser, Johannes Barth, Michael Buback,* Hendrik Kattner, and Philipp Vana \\ Institut für Physikalische Chemie, Georg-August-Universität Göttingen, Tammannstr. 6, D-37077 Göttingen, Germany
}

ABSTRACT: The kinetics of reversible addition-fragmentation chain transfer (RAFT) polymerization of butyl acrylate with ethyl S-thiobenzoyl-2-thiopropionate (ETTP) as the RAFT agent has been studied. The concentrations of propagating $\left(\mathrm{P}^{\bullet}\right)$ and intermediate radicals $\left(\mathrm{INT}^{\circ}\right)$ were measured via highly time-resolved EPR spectroscopy after initiation by a laser single pulse. Predici simulation of experimental data results in rate coefficients for $-40^{\circ} \mathrm{C}$ of $k_{\mathrm{ad}}=(1.4 \pm 0.4) \times 10^{6} \mathrm{~L} \mathrm{~mol}^{-1} \mathrm{~s}^{-1}$, $k_{\beta}=(4.7 \pm 1.5) \mathrm{s}^{-1}$, and $k_{\mathrm{t}}^{\text {cross }}=0.25 \times k_{\mathrm{t}}$, where $k_{\mathrm{t}}$ is the rate coefficient for termination of two $\mathrm{P}^{\bullet}$ species. Fast fragmentation

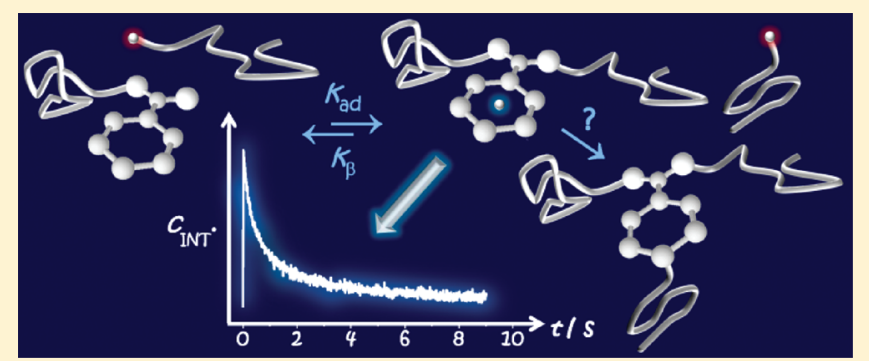
of the intermediate radical is thus observed at this low temperature. Measuring the ratio of $\mathrm{INT}^{\bullet}$ to $\mathrm{P}^{\bullet}$ concentrations during stationary polymerization at -40 and $70^{\circ} \mathrm{C}$ yields $K_{\mathrm{eq}}=k_{\mathrm{ad}} / k_{\beta}$ values of $(2.3 \pm 0.6) \times 10^{5}$ and $75 \pm 15 \mathrm{~L} \mathrm{~mol}^{-1}$, respectively, which correspond to an apparent activation energy difference, $E_{\mathrm{A}}\left(k_{\mathrm{ad}} / k_{\beta}\right)$, of $-49.5 \mathrm{~kJ} \mathrm{~mol}^{-1}$.

\section{INTRODUCTION}

Since its invention in 1998, reversible addition-fragmentation chain transfer $(\mathrm{RAFT})^{1}$ polymerization has proven to be one of the most versatile techniques for producing polymers of defined size and shape. The key steps of the RAFT process are the reversible addition and fragmentation reactions under preand main-equilibrium conditions (see Scheme 1), which are superimposed on a conventional radical polymerization scheme. Under ideal reaction conditions, the concentration of propagating radicals $\left(\mathrm{P}^{\bullet}\right)$ should not be affected by RAFT control, allowing for high rates in RAFT-mediated polymerization.

Considerable induction periods and rate retardation phenomena are, however, observed when dithiobenzoates are used as RAFT agents. Various attempts have been made to explain this rate retardation behavior including slow fragmentation of the RAFT intermediate radical, $\mathrm{INT}^{\bullet}, 2$ cross-termination between $\mathrm{INT}^{\bullet}$ and a growing radical $^{3}$ (see Scheme 1), and a combined model in which cross-termination is assumed to be restricted to very small growing radicals up to chain length three. ${ }^{4}$ Depending on the particular model assumption, widely differing rate coefficients, $k_{\beta}$, have been deduced for fragmentation of $\operatorname{INT}^{\bullet}$. Thus, for dithiobenzoate-mediated styrene polymerizations, $k_{\beta}$ values between $10^{-2}$ and $10^{5} \mathrm{~s}^{-1}$ have been reported for identical polymerization conditions. ${ }^{5-7}$ Recently, Chernikova et al..$^{8}$ used a spin trap method for deriving a rate coefficient of $8 \times 10^{-3} \mathrm{~s}^{-1}$ for fragmentation of a tert-butyl radical from a dithiobenzoate intermediate radical at ambient temperature. It was however not pointed out whether this value for pre-equilibrium conditions applies to polymerizing systems. Moreover, this spin trap strategy remains to be tested under conditions where the addition reaction, to form $\mathrm{INT}^{\circ}$, occurs at a negligible rate as compared to the fragmentation step. Coote and co-workers ${ }^{9-13}$ used $a b$ initio quantum-chemical calculations to obtain equilibrium constants for several model systems. This method is valuable for predicting trends but may run into problems when attempts are made to determine accurate rate coefficients for large open-shell species in condensed phase. The problems associated with dithiobenzoate-mediated polymerization kinetics have been reviewed elsewhere. $^{14,15}$

The direct measurement of the lifetime of the intermediate radicals, $\mathrm{INT}^{\bullet}$, should allow for model discrimination. This kind of information is accessible from studies in which laser single pulse initiation is applied in conjunction with electron paramagnetic resonance (EPR) spectroscopy. ${ }^{16}$ Measuring the deacy of intermediate and propagating radical concentrations allows for the determination of the individual addition, $k_{\mathrm{ad}}$, and fragmentation rate coefficient, $k_{\beta}$. Within a second EPR-based method, the RAFT equilibrium constant, $K_{\mathrm{eq}}\left(=k_{\mathrm{ad}} / k_{\beta}\right)$ is deduced from the measured ratio of $\operatorname{INT}^{\bullet}$ to $\mathrm{P}^{\bullet}$ species via a single fast EPR scan during (pseudo)stationary photoinitiated polymerization. ${ }^{16-18}$ Under conditions of cross-termination between $\mathrm{INT}^{\bullet}$ and $\mathrm{P}^{\bullet}$ occurring at negligible rate, compared to addition and fragmentation, $\mathrm{INT}^{\bullet}$ and $\mathrm{P}^{\bullet}$ coexist in a quasi-equilibrium state, and $K_{\text {eq }}$ may be estimated from $c_{\mathrm{INT}} \cdot / \mathcal{c}_{\mathrm{P}}$. at given RAFT agent concentration, $c_{\mathrm{RAFT}}$, via eq $1 .{ }^{19}$

$$
K_{\mathrm{eq}}=\frac{c_{\mathrm{INT}}}{c_{\mathrm{P}^{\bullet}} \times c_{\mathrm{RAFT}}}
$$

Applying eq 1 , Kwak et al. ${ }^{19}$ reported $K_{\mathrm{eq}}=55 \mathrm{~L} \mathrm{~mol}^{-1}$ for polystyryl dithiobenzoate-mediated RAFT polymerization of styrene at $60{ }^{\circ} \mathrm{C}$. These authors estimated $c_{\mathrm{P}}$. from the rate of

Received: November 2, 2010

Revised: January 28, 2011

Published: March 30, 2011 
Scheme 1. RAFT Pre-equilibrium (1a) and MainEquilibrium (1b) Steps and Cross-Termination Step (2) in RAFT-Mediated Polymerizations

(1a)

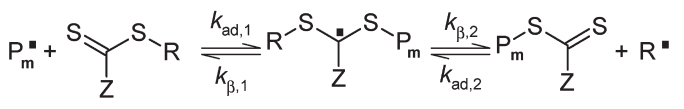

(1b)

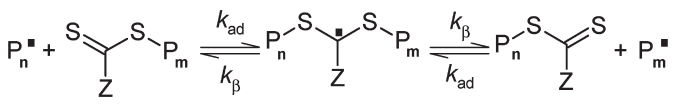

(2)

$$
\mathrm{P}_{\mathrm{n}}^{-S} Y_{\mathrm{Z}}^{\mathrm{S}} \mathrm{P}_{\mathrm{n}}+\mathrm{P}_{\mathrm{n}}^{\cdot} \stackrel{\mathrm{k}_{\mathrm{t}}^{\text {cross }}(n)}{\longrightarrow} \text { termination product }
$$

polymerization and used EPR for detection of $c_{\mathrm{INT}}$. in a separate polymerization experiment.

The decay of $\operatorname{INT}^{\bullet}$ and $\mathrm{P}^{\bullet}$ concentrations, as measured by our time-resolved EPR technique after pulse laser initiation, was fitted on the basis of a simple kinetic scheme via the software package Predici. This procedure requires calibration of the EPR setup in order to obtain absolute radical concentrations, whereas the method for deducing $K_{\text {eq }}$, from the ratio of EPR signal intensities, works without the tedious calibration procedure. Within the present study into dithiobenzoate-mediated polymerization, the two EPR methods were applied simultaneously for BA polymerization in toluene solution with ETTP as the RAFT agent. For evaluation of rate retardation, polymerization rate vs time behavior of BA bulk polymerizations was also studied with cumyl dithiobenzoate (CDB), cyanoisopropyl dithiobenzoate (CPDB), and ETTP as RAFT agents (see Scheme 2). Under main-equilibrium conditions, the resonance-stabilized $\mathrm{INT}^{\bullet}$ species of these RAFT agents (see rhs of Scheme 2) are of identical structure.

\section{EXPERIMENTAL SECTION}

Butyl acrylate (Fluka, purum, 99.5\%, stabilized with hydroquinone monomethyl ether) was purified by passing through a column filled with inhibitor remover (Aldrich). The initiator azobis(isobutyronitrile) (AIBN) was recrystallized from diisopropyl ether prior to use. Toluene (99.5\%, Fluka), the photoinitiator $\alpha$-methyl-4(methylmercapto)- $\alpha$ morpholinopropiophenone (MMMP, 98\%, Aldrich), and the EPR calibration standard 2,2,6,6-tetramethylpiperidine-1-oxyl (TEMPO, $99 \%$, Aldrich) were used as received. $\mathrm{CDB}^{20}$ and $\mathrm{CPDB}^{21}$ were synthesized according to the literature. ETTP was synthesized following the procedure devised by Chong et al. ${ }^{22}$ for synthesis of a similar type of dithiobenzoate: Phenylmagnesium bromide was prepared from bromobenzene $(6.28 \mathrm{~g}, 0.04 \mathrm{~mol})$ and magnesium turnings $(1.00 \mathrm{~g}, 0.04 \mathrm{~mol})$ in dry THF $(30 \mathrm{~mL})$. The solution was heated to $40{ }^{\circ} \mathrm{C}$, and carbon disulfide ( $3.05 \mathrm{~g}, 0.04 \mathrm{~mol}$ ) was added over $15 \mathrm{~min}$ while maintaining the reaction temperature at $40^{\circ} \mathrm{C}$. Ethyl 2-bromopropionate (7.24 g, 0.04 $\mathrm{mol}$ ) was added to the resulting dark brown solution, and the temperature was raised to $80^{\circ} \mathrm{C}$ and maintained for $60 \mathrm{~h}$. Ice-cold water $(50 \mathrm{~mL})$ was added, and the organic products were extracted with diethyl ether $(3 \times 50 \mathrm{~mL})$. The combined organic extracts were washed with water and brine and dried over anhydrous magnesium sulfate. After removal of the solvent and purification by column chromatography on silica with $n$ hexane/diethyl ether $\left(9: 1, R_{\mathrm{f}}=0.21\right)$ as the eluent, ETTP was obtained as a red oil. The purity of the RAFT agents was better than $98 \%$ as verified by ${ }^{13} \mathrm{C}$ and ${ }^{1} \mathrm{H}$ NMR analysis.
Scheme 2. RAFT Agents under Investigation (lhs) and Relevant Resonance Structures (rhs) of the Common Intermediate Radical Species under Main-Equilibrium Conditions of BA Polymerization<smiles>CCOC(=O)C(C)SC(=S)c1ccccc1</smiles>

ETTP<smiles>CC(C)(SC(=S)c1ccccc1)c1ccccc1</smiles><smiles>CC(C)(C#N)SC(=S)c1ccccc1</smiles>
CPDB

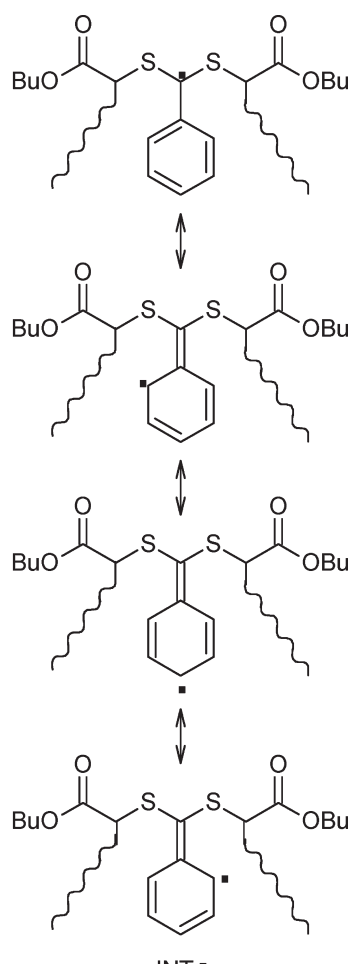

INT *
To compare rate retardation for RAFT agents of similar structure, BA was polymerized in bulk at $70^{\circ} \mathrm{C}$ and different concentrations of CDB, CPDB, and ETTP using AIBN $\left(1.5 \times 10^{-3} \mathrm{~mol} \mathrm{~L}^{-1}\right)$ as the initiator. Monomer conversion was estimated by gravimetry. EPR spectra were also taken during ETTP-mediated BA polymerization. Because of the low initiator concentration, a sweep time of $22 \mathrm{~min}$ was chosen. Radical concentration was calibrated with a solution of TEMPO in BA at $70{ }^{\circ} \mathrm{C}$.

For determination of the individual rate coefficients, solutions of $1.5 \mathrm{~mol} \mathrm{~L}{ }^{-1} \mathrm{BA}$ in toluene with ETTP contents between $7.4 \times 10^{-6}$ and $2.6 \times 10^{-5} \mathrm{~mol} \mathrm{~L}^{-1}$ were prepared. The EPR experiments were carried out at $-40{ }^{\circ} \mathrm{C}$ as detailed elsewhere. ${ }^{16,17}$ For the stationary experiments, which were directed toward $K_{\text {eq }}$ determination, a sweep time of $1.3 \mathrm{~s}$ was selected to avoid significant consumption of the RAFT agent by cross-termination.

Product solutions were collected and subjected to size-exclusion chromatography (SEC) after evaporation of residual monomer. As the eluent, tetrahydrofuran for SEC (THF, Carl Roth, Rotipuran, stabilized with 2,6-di-tert-butyl-4-methylphenol) was used without further purification. Molecular mass distributions were determined by means of SEC using a Waters 515 HPLC pump, three PSS-SDV columns with nominal $5 \mu \mathrm{m}$ particle size and pore sizes of $10^{5}, 10^{3}$, and $10^{2} \AA$, and a Waters 2410 refractive index detector. The SEC setup was operated at $35{ }^{\circ} \mathrm{C}$ with a flow rate of $1 \mathrm{~mL} \mathrm{~min}^{-1}$ and was calibrated against polystyrene standards of narrow polydispersity $\left(M_{\mathrm{P}}=800\right.$ to $2000000 \mathrm{~g} \mathrm{~mol}^{-1}$, Polymer Standards Service). As Mark-Houwink parameters for polyBA, $K=12.2 \times 10^{-5} \mathrm{dL} \mathrm{g}^{-1}$ and $a=0.70^{23}$ were used.

\section{RESULTS AND DISCUSSION}

To check for induction periods and for rate retardation, BA was polymerized in the presence of the RAFT agents CDB, 


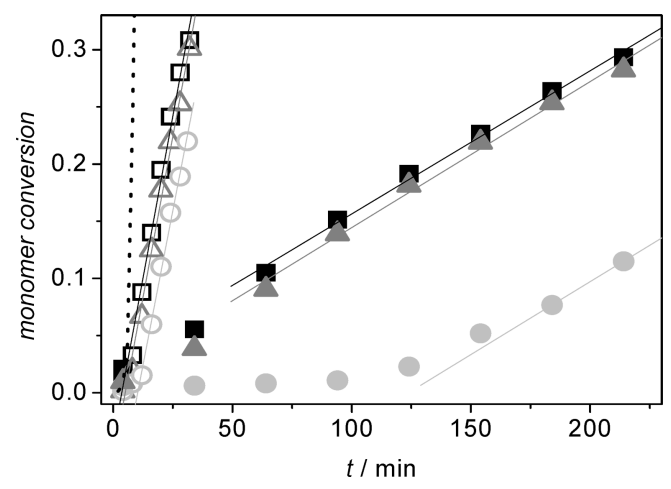

Figure 1. Induction period and rate retardation observed for $\mathrm{BA}$ polymerizations at $70{ }^{\circ} \mathrm{C}$ mediated by ETTP (squares), CPDB (triangles), CDB (circles), and without RAFT agent $(\cdots)$ using AIBN $\left(1.5 \times 10^{-3} \mathrm{~mol} \mathrm{~L}^{-1}\right)$ as the initiator. Open symbols: $c_{\mathrm{RAFT}}=1.5 \times$ $10^{-3} \mathrm{~mol} \mathrm{~L}^{-1}$; closed symbols: $c_{\mathrm{RAFT}}=2.0 \times 10^{-2} \mathrm{~mol} \mathrm{~L}^{-1}$.

CPDB, and ETTP. As can be seen in Figure 1, pronounced rate retardation is observed with the three RAFT agents.

CDB-mediated polymerization at higher RAFT agent concentration exhibits an extended induction period, which is assigned to resonance stabilization of the cumyl radical. This effect is considerably larger than in case of ethyl acrylate and cyanoisopropyl radicals, which are released from the primary intermediate radical species with ETTP and CPDB, respectively. The cumyl radical is less active in reinitiating polymerization. With $\mathrm{CDB}$, the addition of a cumyl radical to $\mathrm{BA}$, under otherwise identical conditions, is by about a factor of 700 slower than the addition of a BA radical to BA (i.e., in homopropagation). ${ }^{24,25}$ This factor reduces to about 10 for addition of the cyanoisopropyl radical to $\mathrm{BA}^{26,27}$ and is smaller than unity in the case of addition of the ethyl acrylate radical to $B A .{ }^{27,28}$ The rate coefficient for addition of the first monomer unit is expected to be well above $k_{\mathrm{p}}$ for subsequent propagation steps of larger growing radicals. ${ }^{29}$ No pre-equilibrium situation is observed in systems where the leaving radical moiety is of similar structure as the propagating radicals, as is the case with ETTP/BA. For CPDB where the leaving group is identical to the initiator fragments from AIBN, inhibition may be interpreted as a decrease in initiator efficiency, since reinitiation by the leaving group does not occur quantitatively until the initial RAFT agent is converted to propagating chain adducts. This effect is more pronounced at higher RAFT agent concentration due to the higher amount of leaving/inhibiting groups. In case of ETTP, reinitiation efficiency of the ethyl acrylate radicals is supposed to be much higher than for AIBN. As a consequence, no inhibition occurs. For $\mathrm{CDB}$ and $\mathrm{CPDB}$, our interpretation is in full agreement with the current understanding of the initialization period as put forward by the Klumperman group: ${ }^{15,30-34}$ The rate-determining step in the initial stage of RAFT polymerization is the addition of the leaving radical moiety to a monomer molecule, unless the leaving group exhibits higher reactivity than the radical fragments from initiator decomposition.

As soon as the initial RAFT agent has been completely transformed into polymeric RAFT species, main-equilibrium conditions apply and the same polymerization rates are observed for the three RAFT agents (Figure 1). This comes as no surprise, as the identical type of intermediate radical occurs under mainequilibrium conditions with $\mathrm{CDB}, \mathrm{CPDB}$, and ETTP (see Scheme 2). Polymerization rates are given by the slope of the

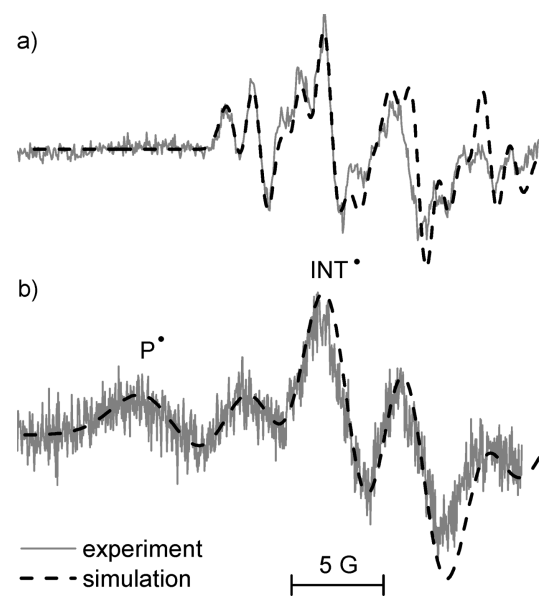

Figure 2. EPR spectrum of the intermediate radical recorded in a $5.2 \mathrm{~s}$ field sweep during an ETTP-mediated polymerization of BA with MMMP as the photoinitiator at $-40^{\circ} \mathrm{C}$. (a) Pseudostationary conditions apply with laser pulsing at a repetition rate of $20 \mathrm{~Hz}$; modulation amplitude: $3 \mathrm{G}$, microwave power: $10 \mathrm{~mW}, c_{\mathrm{ETTP}}=5 \times 10^{-4} \mathrm{~mol} \mathrm{~L}^{-1}$. Simulated spectrum: $g=2.004, \alpha_{\mathrm{H}} / G=1.3(2 \mathrm{H}$, meta $) ; 3.9(2 \mathrm{H}$, ortho); 4.7 (1H, para). (b) EPR spectrum recorded in a $1.3 \mathrm{~s}$ field sweep during a stationary BA polymerization $\left(c_{\mathrm{ETTP}}=2 \times 10^{-5} \mathrm{~mol} \mathrm{~L}^{-1}\right)$ with continuous UV initiation under otherwise identical experimental conditions. The dashed line indicates the best fit of overall EPR contour by summation of the individually simulated EPR spectra for $\mathrm{INT}^{\circ}$ and $\mathrm{P}^{\bullet}$. Because of lower ETTP concentration, the $\mathrm{P}^{\bullet}$ component is more pronounced in (b).

straight-line fits under stationary reaction conditions. They are below the polymerization rate in the absence of RAFT agent $\left(R_{\mathrm{p}}=1.4 \times 10^{-2} \mathrm{~mol} \mathrm{~L}^{-1} \mathrm{~s}^{-} 1\right)$ by a factor of 10 at $c_{\mathrm{RAFT}}=1.5 \times$ $10^{-3} \mathrm{~mol} \mathrm{~L}^{-1}$ and by a factor of 140 at $c_{\mathrm{RAFT}}=2.0 \times 10^{-2} \mathrm{~mol} \mathrm{~L}^{-1}$ $\left(R_{\mathrm{p}}=1.0 \times 10^{-4} \mathrm{~mol} \mathrm{~L}^{-1} \mathrm{~s}^{-1}\right)$.

Because of the close similarity of polymerization rates under main-equilibrium conditions (Figure 1), EPR experiments were carried out only for ETTP, as this RAFT agent exhibits no induction period and is far more stable toward UV and laser irradiation than are CDB and CPDB. The decay of ETTP concentration due to broad-band UV irradiation occurs by less than $1 \%$ within $1.3 \mathrm{~s}$, which is the typical irradiation time of our experiments. No decomposition of the RAFT agent however occurs even by applying 10 laser pulses at $351 \mathrm{~nm}$. To carry out the experiment, only one laser pulse is required. Since ETTP bears an acrylate leaving group, the number of rate coefficients to be fitted by Predici simulations of an acrylate polymerization is lower than, e.g., in CDB-mediated BA polymerization. ${ }^{16}$ The polymerization temperature of $-40{ }^{\circ} \mathrm{C}$ was chosen in order to avoid significant backbiting of the secondary propagating radicals. ${ }^{35}$ EPR spectra measured at higher temperature clearly show midchain radicals. The presence of three types of radicalssecondary chain-end ones, tertiary midchain ones, and RAFT intermediate ones-turns EPR analysis more difficult but poses no principal problem toward the applicability of the novel procedure. A further argument for low-temperature studies comes from the intention of testing slow-fragmentation behavior. Since a significant activation energy is expected for $k_{\beta},{ }^{9}$ the intermediate radical should be extremely long-lived at $-40^{\circ} \mathrm{C}$ in the case of slow fragmentation.

Presented in Figure 2a is the EPR spectrum of the intermediate radical recorded during an ETTP-mediated BA polymerization at $-40^{\circ} \mathrm{C}$ under laser pulsing at a repetition rate of $20 \mathrm{~Hz}$. The 


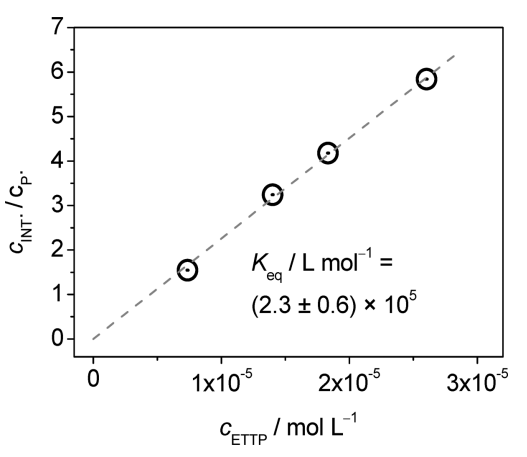

Figure 3. Ratio of intermediate radical and propagating radical concentrations, $c_{\mathrm{INT}} \cdot \mathcal{c}_{\mathrm{P}}$, plotted vs ETTP concentration for BA polymerizations $\left(1.5 \mathrm{~mol} \mathrm{~L}{ }^{-1}\right.$ in toluene $)$ at $-40{ }^{\circ} \mathrm{C}$; photoinitiator: MMMP $\left(1.0 \times 10^{-2} \mathrm{~mol} \mathrm{~L}^{-1}\right)$. The slope of the straight-line fit yields the equilibrium constant, $K_{\text {eq }}$.

essential features of the experimental spectrum are adequately represented by the simulated EPR curve (dashed line). Delocalization of the radical functionality over the phenyl ring is indicated by the hyperfine splitting pattern already reported for styrene and for acrylate polymerizations mediated by dithiobenzoates. ${ }^{19,36-40}$ The EPR spectrum in Figure $2 \mathrm{~b}$ has been recorded under continuous UV initiation under otherwise identical conditions.

From the EPR signals of intermediate and propagating radicals recorded during a single fast scan (Figure $2 \mathrm{~b}$ ), the equilibrium constant, $K_{\text {eq }}$, may be estimated via eq 1 . Because of the shorter sweep time, the spectrum is noisier than the one in Figure 2a. EPR spectra as in Figure $2 b$ were taken at different ETTP concentrations. The measured $c_{\mathrm{INT}} \cdot \mathcal{c}_{\mathrm{P}}$. ratios obtained by deconvolution of the EPR spectra ${ }^{41}$ are plotted vs ETTP concentration in Figure 3. Details about the deconvolution procedure and the coupling constants of propagating radical $\mathrm{P}^{\bullet}$ are given elsewhere. ${ }^{16,17}$ According to eq 1, the slope of the straight line passing through the origin, yields $K_{\mathrm{eq}}=(2.3 \pm 0.6) \times 10^{5} \mathrm{~L} \mathrm{~mol}^{-1}$. The accuracy of $K_{\mathrm{eq}}$ is essentially determined by the error associated with measuring $c_{\mathrm{INT}} \cdot / \mathcal{c}_{\mathrm{P}}$. and depends on the validity of eq 1 under the specific experimental conditions. That eq 1 is indeed applicable will be demonstrated further below. The observed $K_{\text {eq }}$ value is by about 1 order of magnitude above the one found for BA polymerization mediated by trithiocarbonates $^{17}$ and is by 4 orders of magnitude above $K_{\text {eq }}$ for BA polymerized under xanthate control (at $\left.-40{ }^{\circ} \mathrm{C}\right) .{ }^{16}$

Product samples were analyzed via size-exclusion chromatography. The number averages of molar mass, $M_{\mathrm{n}}>700 \mathrm{~g} \mathrm{~mol}^{-1}$, are indicative of main-equilibrium conditions. The $M_{\mathrm{n}}$ values decrease toward higher ETTP concentration. If $K_{\mathrm{eq}}$ would be clearly different for pre-equilibrium and main-equilibrium conditions, the $c_{\mathrm{INT}} \cdot \mathcal{c}_{\mathrm{P}} \cdot$ vs $c_{\mathrm{RAFT}}$ correlation should be nonlinear. This is, however, not what the experimental data indicate. No clear chainlength dependence is observed, which may be due to the fact that the radical which fragments from the addition product of a radical to ETTP is very similar to the growing (secondary) radical of BA polymerization at low temperature. This is not to say that the very first steps of addition and fragmentation are independent of chain length. The experiment is however not sufficiently sensitive to investigate such a dependence under pre-equilibrium conditions.

As mentioned above, the determination of $K_{\mathrm{eq}}$ for BA polymerizations at elevated temperatures is complicated by the occurrence of midchain radicals. However, an apparent equilibrium constant may be obtained at elevated temperatures, e.g., at $70{ }^{\circ} \mathrm{C}$, by determination of $c_{\mathrm{INT}}$. and $c_{\mathrm{P}}$. from two independent experiments: The concentration of secondary propagating radicals, $c_{\mathrm{P}}$, has been determined from the measured rate of polymerization and the known $k_{\mathrm{p}}$ value of these radical species, ${ }^{27,42}$ as detailed in ref 19 . The resulting value is $(5.2 \pm 0.5) \times 10^{-10} \mathrm{~mol}$ $\mathrm{L}^{-1}$ for BA polymerization carried out at a RAFT agent concentration of $c_{\mathrm{RAFT}}=2.0 \times 10^{-2} \mathrm{~mol} \mathrm{~L}^{-1}$. In addition, EPR spectra were taken during ETTP-mediated BA polymerization at $70{ }^{\circ} \mathrm{C}$. $\mathrm{The} \mathrm{INT}^{\bullet}$ concentration is determined by double integration of the associated EPR component to be $(3.9 \pm 0.4) \times 10^{-8} \mathrm{~mol} \mathrm{~L}^{-1}$. The resulting (apparent) equilibrium constant is $(75 \pm 15) \mathrm{L} \mathrm{mol}^{-1}$, which value is close to $K_{\mathrm{eq}}=55 \mathrm{~L} \mathrm{~mol}^{-1}$ as reported by Kwak et al. ${ }^{19}$ for polystyryl dithiobenzoate-mediated styrene polymerization at $60^{\circ} \mathrm{C}$. From the $K_{\text {eq }}$ values for BA polymerization at $-40{ }^{\circ} \mathrm{C}$ and at $70{ }^{\circ} \mathrm{C}$, the difference in activation energies, $E_{\mathrm{A}}\left(k_{\mathrm{ad}} / k_{\beta}\right)=$ " $E\left(K_{\mathrm{eq}}\right)$ " $=-49.5 \mathrm{~kJ} \mathrm{~mol}^{-1}$, is found. This number is in close agreement with the value of $-40.5 \mathrm{~kJ} \mathrm{~mol}^{-1}$ determined by Arita et al. ${ }^{43}$ for CDB-mediated styrene polymerization. In addition, $E_{\mathrm{A}}\left(k_{\mathrm{ad}} / k_{\beta}\right)$ is well within the range of the data from $a b$ initio calculations for various model systems, e.g., between -95 and $-34 \mathrm{~kJ} \mathrm{~mol}^{-1}$ for reaction of $\mathrm{CH}_{3}, \mathrm{CH}_{2} \mathrm{COOCH}_{3}$, $\mathrm{CH}_{2} \mathrm{Ph}$, or $\left.\mathrm{C}\left(\mathrm{CH}_{3}\right)_{2} \mathrm{CN}\right)$ radicals with RAFT agents bearing a $\mathrm{CH}_{3}$ leaving group and a $\mathrm{CH}_{3}$, phenyl, or benzyl Z-group.'

Without further assumptions, the rate coefficients for addition, $k_{\text {ad }}$, and fragmentation, $k_{\beta}$, are not accessible from $K_{\text {eq }}$. These individual rate coefficients may, however, be deduced by measuring the concentrations of both intermediate and propagating radicals, $c_{\mathrm{INT}} \cdot$ and $c_{\mathrm{P}}$, via microsecond time-resolved EPR spectroscopy after laser single pulse initiation and subsequent fitting of the experimental time traces to a kinetic scheme via Predici. In Figure 4, the measured time evolutions of $\mathrm{INT}^{\bullet}$ and $\mathrm{P}^{\bullet}$ concentrations after applying the laser pulse at $t=0$ are shown.

In spite of resonance stabilization of radical functionality over the phenyl ring and the low temperature of $-40{ }^{\circ} \mathrm{C}$, the RAFT intermediate decays on a time scale of a few seconds, signifying that $\mathrm{INT}^{\bullet}$ is a relatively short-lived species. This observation makes slow fragmentation a very unlikely explanation for retardation in dithiobenzoate-mediated polymerization because this model predicts a half-life of more than $10 \mathrm{~s}$ at $60{ }^{\circ} \mathrm{C}$, ${ }^{2}$ which would result in a half-life of hours at $-40{ }^{\circ} \mathrm{C}$. Quantitative evidence is provided by subjecting the experimental radical concentration vs time traces to parameter estimation via the program package Predici (version 6.4.6 on an Intel Core Duo, $1.87 \mathrm{GHz}$ computer). The kinetic scheme, which encompasses initiation, propagation, chain-length-dependent termination, the individual RAFT pre-equilibrium and main-equilibrium reaction steps, and chain-length-dependent cross-termination of the intermediate radical, is detailed in the literature. ${ }^{16}$ It is assumed that, due to chemical similarity of the leaving group of the reaction product from addition of the RAFT agent to the propagating BA radical, the addition and the fragmentation rate coefficients of the ETTP-derived radical should be very similar to the associated rate coefficients of growing BA radicals, i.e., $k_{\mathrm{ad}, 1}=$ $k_{\mathrm{ad}, 2}=k_{\mathrm{ad}}$ and $k_{\beta, 1}=k_{\beta, 2}=k_{\beta}$ (see Scheme 1). Moreover, the leaving group is assumed to add to a monomer molecule, and thus reinitiate, at the same rate as the propagating radical, i.e., $k_{\mathrm{p}}^{\mathrm{rein}}=k_{\mathrm{p}}$. The propagation rate coefficient, $k_{\mathrm{p}}{ }^{27}$ and the chainlength-dependent termination rate coefficient, $k_{\mathrm{t}}(i, i),{ }^{44}$ are known from the literature. The initiation rate coefficient, $k_{\mathrm{i}}$, was assumed to be by 1 order of magnitude above the propagation rate coefficient: $k_{\mathrm{i}}=10 k_{\mathrm{p}}$. 

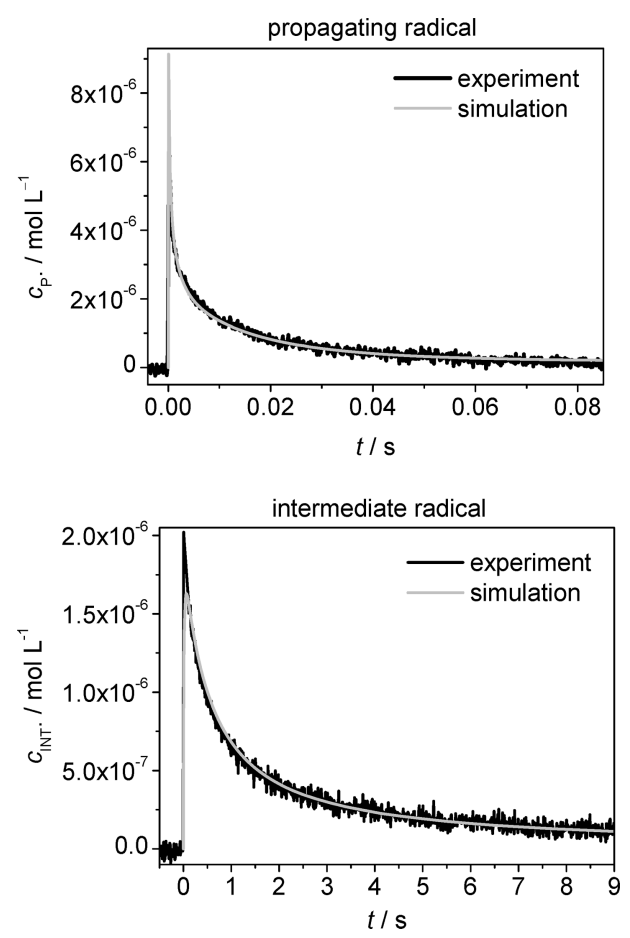

Figure 4. Simulated and experimental concentration vs time traces for propagating and intermediate radicals during $\mathrm{BA}$ polymerization (1.5 mol L ${ }^{-1}$ in toluene) at $-40{ }^{\circ} \mathrm{C}$. The initial ETTP and MMMP concentrations were $2.0 \times 10^{-5}$ and $1.0 \times 10^{-2} \mathrm{~mol} \mathrm{~L}^{-1}$, respectively. The input parameters for Predici simulation were $k_{\mathrm{p}}=2.27 \times$ $10^{3} \mathrm{~L} \mathrm{~mol}^{-1} \mathrm{~s}^{-1}, k_{\mathrm{i}}=2.27 \times 10^{4} \mathrm{~L} \mathrm{~mol}^{-1} \mathrm{~s}^{-1}, c_{\mathrm{R}}^{0}=1.30 \times 10^{-5} \mathrm{~mol} \mathrm{~L}^{-1}$, $k_{\mathrm{t}}(i, i)=1.65 \times 10^{8} \mathrm{~L} \mathrm{~mol}^{-1} \mathrm{~s}^{-1}, \alpha_{\mathrm{s}}=0.85, \alpha_{1}=0.22, i_{\mathrm{c}}=30$, and $k_{\mathrm{t}}^{\text {cross }}(i)=$ $0.25 \times k_{\mathrm{t}}(i, i)$. For explanation of the individual notations see text.

The primary free-radical concentration, $c_{\mathrm{R}}^{0}$, which is almost instantaneously produced by absorption of the laser pulse, is identified with the concentration of initiator fragments at $t=0$. The $c_{\mathrm{R}}^{0}$ value has to be varied within the simulation procedure to fit the maxima of experimental $c_{\mathrm{INT}}$ and $c_{\mathrm{P}}$. traces. The final choice of the parameters $c_{\mathrm{R}}^{0} k_{\mathrm{i}}$, and $k_{\mathrm{ad}, 1}$, however, does not affect the results for the fitted parameters $k_{\mathrm{ad}}$ and $k_{\beta}$, as the impact of the reactions associated with $c_{\mathrm{R}}^{0}, k_{\mathrm{i}}$, and $k_{\mathrm{ad}, 1}$ is essentially restricted to the increasing part of the experimental concentration vs time traces.

So far, no reliable number is available for the cross-termination rate coefficient. Kwak et al. ${ }^{45}$ estimated $k_{\mathrm{t}}^{\text {cross }}$ to be around $0.5 k_{\mathrm{t}}$, thus allowing for rapid cross-termination between radicals of arbitrary size. In contrast, Konkolewicz et al. ${ }^{46}$ assumed that intermediate radicals exclusively terminate with propagating radicals of very short chain length. This assumption is, however, in conflict with results from Monte Carlo simulations, ${ }^{47}$ where the contact probability between radical chain ends and several positions along the arms of star-branched chains with up to six arms was investigated. For a two-arm star, a reduction of the contact probability with radical size according to a power law with an exponent of -0.27 has been found, which number is only slightly above the exponent of -0.16 for the contact probability of the radical chain ends of two linear chains. Thus, the contact probability is not reduced to such an extent as to impede RAFT production of larger star-shaped species. The result from theory is in full agreement with the observed control of RAFT synthesis of star polymers, which requires efficient chain transfer at the center of the star-shaped polymer. ${ }^{48}$ For cross-termination between an intermediate radical and a growing chain, the same shielding effects as for chain transfer processes should operate. Moreover, restricting termination of $\operatorname{INT}^{\bullet}$ species to reaction with very small radicals would be associated with a highly unusual chain-length dependence of this process, for which no physical reason is seen and also no indication is found in the comprehensive review article on chain-length-dependent termination by Barner-Kowollik and Russell. ${ }^{49}$ In addition, Geelen and Klumperman $^{50}$ found indications for 3- and 4-arm stars consisting of long chain arms in RAFT polymerizations. We thus see no justification for ignoring cross-termination of larger propagating radicals with intermediate radicals. The chain-length dependence of $k_{\mathrm{t}}^{\text {cross }}$ is adopted to be identical to the one measured for $k_{\mathrm{t}}$.

To check for the impact of cross-termination, parameter estimates have been carried out for various sizes of relative cross-termination rate, $C_{\text {cross }}=k_{\mathrm{t}}^{\text {cross }} / k_{\mathrm{t}}$, with $C_{\text {cross }}$ being varied from 0 to 1 .

Best fits of both the $c_{\mathrm{INT}}$. and $c_{\mathrm{P}}$. vs time traces from EPR spectroscopy were obtained for $k_{\mathrm{t}}^{\text {cross }}$ being in the range $0.2 k_{\mathrm{t}}$ to $0.3 k_{\mathrm{t}}$. The lower value is determined by the fitting quality of $c_{\mathrm{P}}$. vs $t$ and the upper value by the $c_{\mathrm{INT}}$. vs $t$ fit; i.e., the decay of $\mathrm{P}^{\bullet}$ suggests $C_{\text {cross }} \geq 0.2$, whereas the decay of $\operatorname{INT}^{\bullet}$ is best fitted by $C_{\text {cross }} \leq 0.3$. Simultaneous fitting of both concentration vs time traces thus results in a narrow range for the size of crosstermination: $C_{\text {cross }}=0.25 \pm 0.05$. Because of the need for calibration of the EPR setup and because of reduced signal-tonoise quality of the spectra, the accuracy of radical concentration measurement is estimated to be about $20 \%$. Simulations of the experimental concentration vs time traces have thus been carried out for various combinations of potential uncertainty, i.e., assuming $c_{\mathrm{INT}}$. and $c_{\mathrm{P}}$. to be either as calibrated or by $10 \%$ below or above this value.

Plotted in Figure 5 are the so-obtained values of addition rate coefficient, $k_{\mathrm{ad}}$, and fragmentation rate coefficient, $k_{\beta}$, (upper part), and the resulting values of equilibrium constant, $K_{\mathrm{eq}}=k_{\mathrm{ad}} /$ $k_{\beta}$ (lower part). The smaller symbols indicate the results for a particular combination of the concentrations being taken as calibrated or as $10 \%$ above or below this value. The larger symbols indicate the mean value obtained for the 9 combinations selected at identical $C_{\text {cross. }}$. The error bars indicate the range of $k_{\mathrm{ad}}, k_{\beta}$, and $K_{\mathrm{eq}}$ values resulting as simulation results for $c_{\mathrm{INT}} \cdot$ and $c_{\mathrm{P}}$. varying by $\pm 10 \%$. Toward increasing $C_{\text {cross }}, k_{\beta}$ slightly decreases and $K_{\text {eq }}$ increases, whereas $k_{\text {ad }}$ is almost insensitive toward the variation of $C_{\text {cross }}$ within the range $0.2-0.3$. The rate coefficients obtained for $C_{\text {cross }}=0.25$, which allows the best fit of both radical concentration profiles (see Figure 4), are $k_{\mathrm{ad}}=$ $(1.4 \pm 0.4) \times 10^{6} \mathrm{~L} \mathrm{~mol}^{-1} \mathrm{~s}^{-1}$ and $k_{\beta}=4.7 \pm 1.5 \mathrm{~s}^{-1}$.

From these $k_{\text {ad }}$ and $k_{\beta}$ values, the equilibrium constant at $40{ }^{\circ} \mathrm{C}$ is obtained to be $K_{\mathrm{eq}}=(3.4 \pm 0.6) \times 10^{5} \mathrm{~L} \mathrm{~mol}^{-1}$. This number is in satisfactory agreement with $K_{\mathrm{eq}}=(2.3 \pm 0.6) \times$ $10^{5} \mathrm{~L} \mathrm{~mol}^{-1}$, as obtained from the measured ratio of $\operatorname{INT}^{\bullet}$ to $\mathrm{P}^{\bullet}$ concentrations under stationary polymerization conditions (see above). In Figure 5, the range of uncertainty quoted for $K_{\mathrm{eq}}$ is indicated by the shaded area. The data show that $K_{\text {eq }}$ estimated from $k_{\text {ad }}$ and $k_{\beta}$ for $C_{\text {cross }}=0.25$ is not significantly different from the corresponding value deduced from experimentally determined $c_{\mathrm{INT}} \cdot / c_{\mathrm{P}}$. The RAFT model thus appears to adequately describe the polymerization kinetics and thus should be well suited for determination of $k_{\mathrm{ad}}$ and $k_{\beta}$.

The obtained $k_{\text {ad }}$ and $k_{\beta}$ values may be used to check whether the reaction conditions of the stationary experiments were 


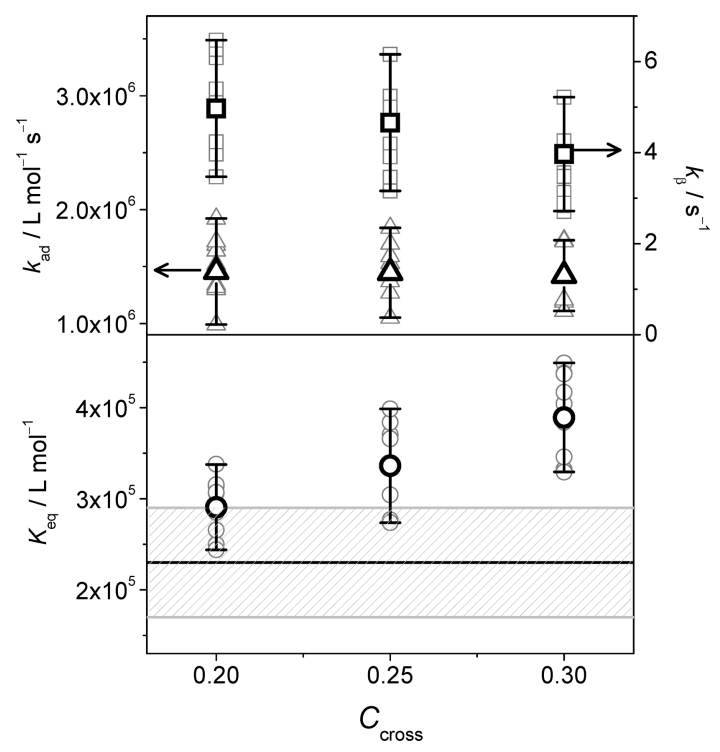

Figure 5. Results from fitting the experimental trace for ETTPmediated BA polymerization at $-40{ }^{\circ} \mathrm{C}$ for various adopted $C_{\text {cross }}$ values. Upper part: $k_{\text {ad }}$ (triangles) and $k_{\beta}$ (squares); lower part: $K_{\mathrm{eq}}$ (circles). The shaded area indicates $K_{\mathrm{eq}}=(2.3 \pm 0.6) \mathrm{L} \mathrm{mol}^{-1} \mathrm{~s}^{-1}$ which value has been deduced from measuring $c_{\mathrm{INT}} \cdot / c_{\mathrm{P}}$. during stationary RAFT polymerization.

adequate for estimating $K_{\mathrm{eq}}$ via eq 1, i.e., whether the rate of cross-termination, $r_{t}^{\text {cross }}$, is indeed negligible as compared to the addition and fragmentation rates, $r_{\mathrm{ad}}$ and $r_{\beta}$. The absolute concentrations of $\mathrm{INT}^{\bullet}$ and $\mathrm{P}^{\bullet}$ are known from the EPR spectra. The maximum value of $r_{t}^{\text {cross }}$ was estimated by implementing $k_{\mathrm{t}}^{\text {cross }}=k_{\mathrm{t}}(1,1)$, which refers to the upper limit of termination taking place between a propagating and an intermediate radical, both of chain length unity. In order to consider the worst case scenario also for addition and fragmentation, both rates were estimated for the lowest $c_{\text {ETTP. Even under these conditions, }}$ $r_{\mathrm{t}}^{\text {cross }}$ is by about 1 order of magnitude below $r_{\mathrm{ad}}$ and $r_{\beta}$, thus verifying the validity of using eq 1 for the ETTP concentration range selected for our experiments.

Via the activation energy $E_{\mathrm{A}}\left(k_{\mathrm{ad}} / k_{\beta}\right)=-49.5 \mathrm{~kJ} \mathrm{~mol}^{-1}$ (see above) and assuming that $k_{\text {ad }}$ is associated with a low activation energy, e.g., of $8.4 \mathrm{~kJ} \mathrm{~mol}^{-1}$, as suggested by $a b$ initio quantum calculations for the addition of small radicals to dithioester compounds, ${ }^{9}$ the activation energy of $k_{\beta}$ is estimated to be $E_{\mathrm{A}}\left(k_{\beta}\right)=56.9 \mathrm{~kJ} \mathrm{~mol}^{-1}$. This number together with $k_{\beta}$ measured for $-40{ }^{\circ} \mathrm{C}$ results in a fragmentation rate coefficient of $3.1 \times$ $10^{4} \mathrm{~s}^{-1}$ at $60^{\circ} \mathrm{C}$, which is by orders of magnitude above $k_{\beta}$ values predicted by the slow fragmentation model; e.g., $k_{\beta}=10^{-2} \mathrm{~s}^{-1}$ has been reported for CDB-mediated styrene polymerization at $60{ }^{\circ} \mathrm{C} .{ }^{5}$ It is very unlikely that polymerizing styrene rather than BA may be responsible for this difference by about 5 orders of magnitude. Moreover, if the monomers matters, one would expect that, with identical RAFT agent, $k_{\beta}$ is higher for styrene than for BA, as the styryl radical is stabilized by delocalization of radical functionality over the aromatic ring.

\section{CONCLUSION}

Fast fragmentation has been observed in dithiobenzoatemediated polymerization of $\mathrm{BA}$, although $k_{\beta}$ is by a factor of 10 below the corresponding number in trithiocarbonatemediated BA polymerization. ${ }^{\$ 1}$ Slow fragmentation provides no explanation for rate retardation in dithiobenzoate-mediated BA polymerization. Best fits of the measured radical concentration vs time profiles were obtained assuming $k_{\mathrm{t}}^{\text {cross }}=0.25 k_{\mathrm{t}}$. In ongoing work, our method will be further refined to allow for even more detailed insight into the reaction pathway.

The results obtained for ETTP should also hold for CDB- and CPDB-mediated BA polymerization under main-equilibrium conditions. The differences of initialization behavior observed for the three dithiobenzoates may be attributed to their specific leaving groups, which result in different fragmentation and reinitiation rates of the primary species. The EPR techniques presented here may also be used for investigation into polymerization mediated by other RAFT agents such as xanthates ${ }^{16}$ or trithiocarbonates. ${ }^{17}$

\section{AUTHOR INFORMATION}

\section{Corresponding Author}

*E-mail: mbuback@uni-goettingen.de.

\section{ACKNOWLEDGMENT}

We acknowledge the early contributions of Prof. T. Junkers to time-resolved EPR analysis of RAFT polymerization during his Ph.D. period in the Goettingen group. A fellowship from the Fonds der Chemischen Industrie (to J.B.) is gratefully acknowledged. P.V. is thankful for a Heisenberg-Professorship (DFG).

\section{REFERENCES}

(1) Chiefari, J.; Chong, Y. K.; Ercole, F.; Krstina, J.; Jeffery, J.; Le, T. P. T.; Mayadunne, R. T. A.; Meijs, G. F.; Moad, C. L.; Moad, G.; Rizzardo, E.; Thang, S. H. Macromolecules 1998, 31, 5559-5562.

(2) Feldermann, A.; Coote, M. L.; Stenzel, M. H.; Davis, T. P.; Barner-Kowollik, C. J. Am. Chem. Soc. 2004, 126, 15915-15923.

(3) Monteiro, M. J.; de Brouwer, H. Macromolecules 2001, 34, 349-352.

(4) Konkolewicz, D.; Hawkett, B. S.; Gray-Weale, A.; Perrier, S. Macromolecules 2008, 41 (17), 6400-6412.

(5) Barner-Kowollik, C.; Quinn, J. F.; Morsley, D. R.; Davis, T. P. J. Polym. Sci., Part A: Polym. Chem. 2001, 39, 1353-1365.

(6) Wang, A. R.; Zhu, S. P.; Kwak, Y. W.; Goto, A.; Fukuda, T.; Monteiro, M. S. J. Polym. Sci., Part A: Polym. Chem. 2003, 41, 2833-2839.

(7) Barner-Kowollik, C.; Coote, M. L.; Davis, T. P.; Radom, L.; Vana, P. J. Polym. Sci., Part A: Polym. Chem. 2003, 41, 2828-2832.

(8) Chernikova, E.; Golubev, V.; Filippov, A.; Lin, C. Y.; Coote, M. L. Polym. Chem. 2010, 1, 1437-1440.

(9) Coote, M. L. J. Phys. Chem. A 2005, 109, 1230-1239.

(10) Coote, M. L.; Izgorodina, E. I.; Krenske, E. H.; Busch, M.; Barner-Kowollik, C. Macromol. Rapid Commun. 2006, 27, 1015-1022.

(11) Coote, M. L.; Krenske, E. H.; Izgorodina, E. I. Macromol. Rapid Commun. 2006, 27, 473-497.

(12) Izgorodina, E. I.; Coote, M. L. Macromol. Theory Simul. 2006, 15, 394-403.

(13) Lin, C. Y.; Coote, M. L. Aust. J. Chem. 2009, 62, 1479-1483.

(14) Barner-Kowollik, C.; Buback, M.; Charleux, B.; Coote, M. L.; Drache, M.; Fukuda, T.; Goto, A.; Klumperman, B.; Lowe, A. B.; Mcleary, J. B.; Moad, G.; Monteiro, M. J.; Sanderson, R. D.; Tonge, M. P.; Vana, P. J. Polym. Sci., Part A: Polym. Chem. 2006, 44, 5809-5831.

(15) Klumperman, B.; van den Dungen, E. T. A.; Heuts, J. P. A.; Monteiro, M. J. Macromol. Rapid Commun. 2010, 31, 1846-1862.

(16) Meiser, W.; Buback, M.; Barth, J.; Vana, P. Polymer 2010, 51, 5977-5982.

(17) Barth, J.; Buback, M.; Meiser, W.; Vana, P. Macromolecules 2010, 43, 51-54. 
(18) Buback, M.; Hesse, P.; Junkers, T.; Vana, P. Macromol. Rapid Commun. 2006, 27, 182-187.

(19) Kwak, Y.; Goto, A.; Tsujii, Y.; Murata, Y.; Komatsu, K.; Fukuda, T. Macromolecules 2002, 35, 3026-3029.

(20) Perrier, S.; Barner-Kowollik, C.; Quinn, J. F.; Vana, P.; Davis, T. P. Macromolecules 2002, 35, 8300-8306.

(21) Weber, W. G.; McLeary, J. B.; Sanderson, R. D. Tetrahedron Lett. 2006, 47, 4771-4774.

(22) Chong, Y. K.; Krstina, J.; Le, T. P. T.; Moad, G.; Postma, A.; Rizzardo, E.; Thang, S. H. Macromolecules 2003, 36, 2256-2272.

(23) Hutchinson, R. A.; McMinn, J. H.; Paquet, D. A.; Beuermann, S.; Jackson, C. Ind. Eng. Chem. Res. 1997, 36, 1103-1113.

(24) McManus, N. T.; Penlidis, A.; Dube, M. A. Polymer 2002, 43, 1607-1614.

(25) Coote, M. L.; Davis, T. P. Macromolecules 1999, 32, 4290-4298.

(26) Fischer, H.; Radom, L. Angew. Chem., Int. Ed. 2001, 40, 1340-1371.

(27) Buback, M.; Kurz, C. H.; Schmaltz, C. Macromol. Chem. Phys. 1998, 199, 1721-1727.

(28) de Kock, J. B. L. Chain-Length Dependent Bimolecular Termination in Free-Radical Polymerization. PhD Thesis, Technical University of Eindhoven, Eindhoven, 1999.

(29) Gridnev, A. A.; Ittel, S. D. Macromolecules 1996, 29, 5864-5874.

(30) McLeary, J. B.; McKenzie, J. M.; Tonge, M. P.; Sanderson, R. D.; Klumperman, B. Chem. Commun. 2004, 17, 1950-1951.

(31) McLeary, J. B.; Calitz, F. M.; McKenzie, J. M.; Tonge, M. P.; Sanderson, R. D.; Klumperman, B. Macromolecules 2004, 37, 2383-2394.

(32) McLeary, J. B.; Calitz, F. M.; McKenzie, J. M.; Tonge, M. P.; Sanderson, R. D.; Klumperman, B. Macromolecules 2005, 38, 3151-3161.

(33) McLeary, J. B.; Tonge, M. P.; Klumperman, B. Macromol. Rapid Commun. 2006, 27, 1233-1240.

(34) van den Dungen, E. T. A.; Matahwa, H.; McLeary, J. B.; Sanderson, R. D.; Klumperman, B. J. Polym. Sci., Part A: Polym. Chem. 2008, 46, 2500-2509.

(35) Willemse, R. X. E.; van Herk, A. M.; Panchenko, E.; Junkers, T.; Buback, M. Macromolecules 2005, 38, 5098-5103.

(36) Hawthorne, D. G.; Moad, G.; Rizzardo, E.; Thang, S. H. Macromolecules 1999, 32, 5457-5459.

(37) Du, F. S.; Zhu, M. Q.; Guo, H. Q.; Li, Z. C.; Li, F. M.; Kamachi, M.; Kajiwara, A. Macromolecules 2002, 35, 6739-6741.

(38) Calitz, F. M.; Tonge, M. P.; Sanderson, R. D. Macromolecules 2003, 36, 5-8.

(39) Chernikova, E.; Morozov, A.; Leonova, E.; Garina, E.; Golubev, V.; Bui, C. O.; Charleux, B. Macromolecules 2004, 37, 6329-6339.

(40) Drache, M.; Schmidt-Naake, G.; Buback, M.; Vana, P. Polymer 2005, 46, 8483-8493.

(41) Sato, E.; Emoto, T.; Zetterlund, P. B.; Yamada, B. Macromol. Chem. Phys. 2004, 205, 1829-1839.

(42) Barner-Kowollik, C.; Gunzler, F.; Junkers, T. Macromolecules 2008, 41, 8971-8973.

(43) Arita, T.; Buback, M.; Vana, P. Macromolecules 2005, 38, 7935-7943.

(44) Barth, J.; Buback, M.; Hesse, P.; Sergeeva, T. Macromol. Rapid Commun. 2009, 30, 1969-1974.

(45) Kwak, Y.; Goto, A.; Fukuda, T. Macromolecules 2004, 37, 1219-1225.

(46) Konkolewicz, D.; Hawkett, B. S.; Gray-Weale, A.; Perrier, S. J. Polym. Sci., Part A: Polym. Chem. 2009, 47, 3455-3466.

(47) Frohlich, M. G.; Vana, P.; Zifferer, G. J. Chem. Phys. 2007, 127, 164906.

(48) Boschmann, D.; Edam, R.; Schoenmakers, P. J.; Vana, P. Polymer 2008, 49, 5199-5208.

(49) Barner-Kowollik, C.; Russell, G. T. Prog. Polym. Sci. 2009, 34, 1211-1259.

(50) Geelen, P.; Klumperman, B. Macromolecules 2007, 40, 3914-3920.

(51) Meiser, W. Unpublished results. 